\title{
EL RECLUTAMIENTO DE LOS DOCENTES EN ARGENTINA: UNA APROXIMACIÓN A PARTIR DE LA OCUPACIÓN DE SUS CÓNYUGES*
}

\author{
RICARDO DONAIRE ${ }^{* *}$
}

RESUMEN: Tradicionalmente ha sido habitual en Argentina la caracterización de los docentes como parte de las clases medias o de la pequeña burguesía, según la perspectiva teórica. Se suele fundamentar esta caracterización principalmente en la composición predominantemente femenina de la docencia y en su carácter de cónyuges de aquella porción de población que ocupa "posiciones relativamente importantes en la estructura social". Sin embargo, pocos estudios han intentado dar cuenta de esta hipótesis (sea para confirmarla o refutarla) y la mayoría de los que lo han intentado se han basado en muestras no representativas. En este trabajo intentaremos avanzar en una caracterización a partir de datos del censo nacional de población del 2001 y conceptualizar los resultados en relación a la existencia de posibles procesos de transformación de la posición de los docentes en la estructura social.

Palabras clave: Docente. Posición social. Estructura social.

\section{THE RECRUITMENT OF TEACHERS IN ARGENTINA:}

\section{AN APPROACH ON OCCUPATION OF THEIR SPOUSES}

\begin{abstract}
In Argentina, teachers have traditionally been characterized as part of the middle class or the petty bourgeoisie, depending on the theoretical perspective. This characterization is usually based on the predominantly female composition of teachers as a group and on their character of wives of that portion of the population that occupies "relatively important positions in the social structure". However, few studies have attempted to account for this hypothesis (either to support it or refute it) and most of them are based on unrepresentative samples. The objective of this paper is to develop a characterization based on data from the national population census of 2001 and a conceptualization of the results regarding the existence of possible processes of change in the position of teachers in social structure.
\end{abstract}

Key words: Teacher. Social position. Social structure.

Este trabajo presenta resultados parciales del proyecto "La posición social de los docentes en Argentina. Un análisis comparativo entre diferentes regiones".

* Doctor en Ciencias Sociales e investigador asistente del Consejo de Investigaciones Científicas y Técnicas de la República Argentina (Conicet). E-mail: ricdonaire@gmail.com 
Le RECRUtement des Professeurs en Argentine: UNE APPROXIMATION A PARTIR DE L'OCCUPATION DE LEUR CONJOINT(E)

\begin{abstract}
RÉSUMÉ: Traditionnellement, il était habituel en Argentine de qualifier les professeurs comme faisant partie des classes moyennes ou de la petite bourgeoisie, selon la perspective théorique. Il est d'usage de fonder cette catégorisation principalement sur la composition à prédominante féminine des professeurs et sur la caractéristique de conjoints appartenant à cette portion de la population qui occupent des "positions relativement importantes dans la structure sociale". Néanmoins, peu d'études ont tenté de rendre compte de cette hypothèse (que ce soit pour la réfuter ou pour la confirmer) et la plupart de ceux qui s'y sont essayé se sont appuyés sur des exemples non représentatifs. Dans ce travail, nous essayerons d'avancer dans une catégorisation à partir de données du recensement national de la population de 2001 et de conceptualiser les résultats en relation avec l'existence de possibles processus de transformation de la position des professeurs dans la structure sociale.
\end{abstract}

Mots-clés: Professeur. Position sociale. Structure sociale.

\title{
Introducción
}

7 radicionalmente ha sido habitual en Argentina la caracterización de los docentes como parte de las clases medias o de la pequeña burguesía, según la

1 perspectiva teórica. A pesar de que, especialmente a partir de la década del noventa, se desarrolló cierto debate respecto del posible "empobrecimiento" de este grupo, no ha variado la caracterización general como parte de las "clases medias".

Un repaso general por alguno de los estudios que intentan abordar la cuestión de la posición social de los docentes señala que:

Las investigaciones que tocan esta temática coinciden en que los docentes pertenecen, en la década del noventa, a los sectores medios y medio-bajos de la sociedad, lo que pone en evidencia que están llegando a este puesto sectores diferentes a los que históricamente lo hacían. El origen social de los docentes ha descendido en las últimas décadas y esto es compatible con el descenso del imaginario social de la profesión docente. (LLOMOVATE, 1995, p. 157)

Este "descenso social" suele ser caracterizado como un proceso de "empobrecimiento" de las "clases medias", el cual habría comenzado a mediados de la década del setenta (y se habría acentuado posteriormente durante los noventa).

Con la creciente pauperización de los sectores medios... algunos sectores no se quedan más que con su propio trabajo para la subsistencia. No es extraño escuchar entre las maestras mujeres que mientras antes su sueldo era una 'ayuda' frente a lo obtenido por el esposo, en la actualidad ese mismo salario, aunque pobre, se convirtió en un sostén principal. (NARODOWSKI, 1990, p. 21-22) 
En este sentido, "desde el punto de vista de sus expectativas materiales, las maestras y maestros argentinos habrían participado de un proceso de reestructuración social, caracterizado por el empobrecimiento de los sectores medios (BRASLAVSKY; BIRGIN, 1995, p. 75)".

Otros estudios más abarcativos han señalado que este "empobrecimiento" ha resultado más bien en cierta "heterogeneidad" de los docentes como grupo, pero sin negar su adscripción mayoritaria a la "clase media". De esta manera, se puede afirmar que:

Este país vivió durante los años noventa un profundo proceso de reestructuración de su economía, que trajo como consecuencia un empobrecimiento masivo de la población y una caída de los niveles de vida de las clases medias. Los docentes fueron víctimas privilegiadas de esta decadencia social. (TENTI FANFANI, 2005, p. 57)

De todas formas, a pesar de este empobrecimiento, la docencia se mantendría como un empleo de "clases medias". Por caso,

[...] el empleo docente, una opción profesional que ya se encontraría en parte encausada desde la elección de una de las variantes de educación formal, desempeña una función más destacada como salida del empleo para las mujeres de las clases medias, más allá de que la elección por la carrera docente haya o no sido el canal de movilidad social. (MARSHALL, 1999, p. 10)

Esta opción por la docencia se ha confirmado en las caracterizaciones referidas a los estudiantes que se forman para ser docentes: “[...] los estudiantes de magisterio provienen, en su mayoría, de diferentes estratos de las llamadas 'clases medias'" (DAVINI; ALLIAUD, 1995, p. 40-41). Otras investigaciones también coinciden en la caracterización de estos estudiantes como provenientes de los "sectores medios bajos" (PINEAU et al., 2003, p. 9).

Esta caracterización respecto de la posición social de los docentes, y por extensión de todos aquellos ocupados en tareas de carácter intelectual, especialmente si se encuentran insertos en relaciones salariales, no es nueva ni se restringe exclusivamente a la Argentina. Se enmarca en un debate más amplio respecto a la posible existencia de un proceso de proletarización de estas "capas medias" y a qué características asume dicho proceso. ${ }^{1}$ De ahí que buena parte de las investigaciones reseñadas partan de la contraposición entre los rasgos que asumen los docentes en tanto profesionales, funcionarios o expertos y aquellos que hacen a su carácter de trabajadores asalariados.

Sin embargo, a pesar de la importancia dada a esta contraposición, en la mayor parte de estos estudios no se retoman los desarrollos propuestos por las teorías 
de la proletarización, y es tal vez por esto, que el análisis del desenvolvimiento de este proceso haya quedado reemplazado por el análisis de distintos aspectos del proceso de "empobrecimiento". De ahí que la caracterización de los docentes como "clase media" no aparezca como problema y que, en todo caso, la polémica gire más bien respecto a su ubicación o no entre las capas pobres de la misma. Tal vez por esta razón, el uso que se ha generalizado del concepto de proletarización, al menos en Argentina, remite no tanto a un proceso con rasgos específicos sino a una manera más de denominar a las formas generales en que se presenta el empobrecimiento, ya se trate de la degradación de las condiciones de vida o de trabajo.

En buena medida, esta caracterización sobre la posición social de los docentes se ha fundamentado principalmente en la composición predominantemente femenina de la docencia y en su tradicional carácter de cónyuges de aquella porción de población que ocupa "posiciones relativamente importantes en la estructura social". Sin embargo, pocos estudios han intentado dar cuenta de esta hipótesis (sea para confirmarla o refutarla) y la mayoría de los que lo han intentado, por un lado, no explicitan las nociones utilizadas para la conceptualización de los diferentes "estratos" o "capas" sociales, y por otro, se han basado en muestras no representativas. ${ }^{2}$

Como resultado de una investigación propia realizada en la Ciudad de Buenos Aires en el año 2007 a partir de una muestra representativa, se pudo observar que la mayor parte de los docentes tenía alguna relación familiar con porciones de población correspondientes a la pequeña burguesía, especialmente a sus capas acomodadas. En el caso de los docentes con cónyuge o pareja, en alrededor del $70 \%$ de los casos se trataba de patrones de grandes, medianas y pequeñas empresas, asalariados directivos o de jefatura de establecimientos privados o públicos, profesionales, docentes y similares asalariados o independientes y personal técnico de gestión administrativa contable asalariado. ${ }^{3}$

Sin embargo, una de las características distintivas de la Ciudad de Buenos Aires es precisamente el alto peso relativo que alcanza la pequeña burguesía acomodada en su estructura social. Esta capa social representaba en 2001 casi un 30\% de la población de la Ciudad, mientras que en el conjunto del país su peso apenas superaba el 16\% (DONAIRE; ROSATI, 2010). Un primer ejercicio comparativo a partir de datos censales mostró que mientras en la Ciudad de Buenos Aires era posible adjudicar a un $50 \%$ de las docentes mujeres cónyuges un reclutamiento desde las capas superiores de la burguesía, en el resto de las jurisdicciones del país esta proporción excepcionalmente llegaba a apenas a rondar el 40\% (DONAIRE, 2010b). Si los resultados alcanzados sobre los docentes de la Ciudad no pueden ser generalizados, ¿cómo caracterizar a los docentes del conjunto del país? 


\section{Aspectos metodológicos}

Para responder esta pregunta realizamos el presente ejercicio, utilizando como fuente, información procesada a partir de la base de datos correspondiente al Censo de Población, Hogares y Vivienda realizado en Argentina en el 2001. Desafortunadamente datos similares correspondientes al último censo de población del año 2010 aún no se encuentran disponibles. Por ende, a futuro al momento de su análisis deberá considerarse hasta qué punto las transformaciones sociales en el lapso transcurrido entre ambos censos han incidido, y en qué grado y de qué manera, en la extracción social de los docentes, más aún considerando que los datos del año 2001 están afectados por una coyuntura de crisis que alcanzaría su punto culminante a fines de ese mismo año. De todas formas, a pesar de la distancia temporal respecto del momento al que refieren los datos aquí analizados, por un lado, no existen elementos que indiquen desde entonces un cambio abrupto en el reclutamiento de los docentes, ${ }^{4}$ y por otro, debe considerarse que fenómenos como el que estamos analizando corresponden al movimiento orgánico de la estructura social más que a movimientos ocasionales o "de coyuntura" (retomando la distinción clásica de Gramsci, 1997). En este sentido, es probable que, a grandes rasgos, la información proporcionada continúe siendo vigente.

Por otra parte, debe aclararse que la fuente utilizada, permite sólo una aproximación limitada a la cuestión del reclutamiento, puesto que brinda información exclusivamente respecto de la composición de los hogares actuales a los que pertenecen los docentes (y no de los hogares de procedencia). Sin embargo, además de que una de las ventajas de esta fuente reside en que se trata de la única que permite acceder a información representativa de la totalidad de la población de referencia en el país, ${ }^{5}$ la cuestión del reclutamiento de este grupo social ha sido generalmente analizada en especial relación a la composición mayoritariamente femenina de dicha ocupación y su situación de cónyuges del jefe de hogar, características que se ha tomado como indicador de la posición social, como hemos señalado anteriormente. De ahí que nuestro análisis se centre precisamente en la población de docentes mujeres que ocupan el lugar de cónyuges del jefe de hogar en el que habitan.

Los docentes aparecen clasificados censalmente como "trabajadores de la educación". La estadística oficial argentina considera que los maestros y profesores de los niveles de educación inicial, primario, secundario y terciario y los de la educación no formal realizan tareas de calificación técnica. En cambio, los profesores y auxiliares universitarios y de conservatorio son consideradas ocupaciones de calificación profesional. La mayor parte $(95 \%)$ de la población cuya ocupación principal es la docencia forma parte del primer grupo. Por esta razón delimitamos como aproximación a los docentes el grupo conformado por los trabajadores asalariados 
de la educación de calificación técnica. Para evitar posibles confusiones, aclaramos que la categoría "trabajadores de la educación" refiere excluyentemente al tipo de ocupaciones anteriormente enumeradas o similares. Es decir, no se incluye aquí a las restantes ocupaciones que participan de enseñanza como rama de actividad (personal de dirección y gestión, personal de apoyo, personal de limpieza y de maestranza, etc.), las cuales se encuentran clasificadas bajo otras categorías censales.

\section{Cuadro 1}

Docentes asalariados según residencia, sexo y relación de parentesco: Argentina (2001)

\begin{tabular}{|c|c|c|c|c|}
\hline Residencia & Sexo & Relación de parentesco & $\mathrm{N}$ & $\%$ \\
\hline \multicolumn{3}{|c|}{ En instituciones colectivas } & 3.501 & 0,6 \\
\hline \multirow{6}{*}{ En hogares } & \multicolumn{2}{|l|}{ Varones } & 114.239 & 18,6 \\
\hline & \multirow{5}{*}{ Mujeres } & Jefa de hogar & 92.294 & 15,0 \\
\hline & & Cónyuge & 288.215 & 47,0 \\
\hline & & Hija/ Hijastra & 98.436 & 16,0 \\
\hline & & Otras & 16.676 & 2,7 \\
\hline & & Total de mujeres en hogares & 495.621 & 80,8 \\
\hline & & Total & 613.361 & 100,0 \\
\hline
\end{tabular}

Fuente: elaboración propia en base a Censo Nacional de Población, Hogares y Vivienda (2001).

De esta manera, el conjunto de quienes declaran como ocupación la docencia está conformado por aproximadamente 600 mil personas, de las cuales poco más del $80 \%$ son mujeres que residen en hogares. A su vez, más de la mitad de estas mujeres docentes ocupan la posición de cónyuge del jefe de los hogares donde habitan.

\section{Caracterización de los jefes de hogar según su ocupación principal}

Nuestro análisis se centra precisamente en este grupo de alrededor de 290 mil docentes mujeres, y por ende, refiere entonces sólo a una porción del conjunto total de los docentes. Por lo tanto, los resultados del análisis no pueden ser inmediatamente generalizados al conjunto. Más bien, se trata, por un lado, de delimitar con mayor precisión el peso de esta población de "mujeres cónyuges" entre los docentes, y por otro, de avanzar en el conocimiento existente sobre su caracterización, respecto de la cual, como hemos dicho, sólo existe información escasa, dispersa y parcial, a partir de la cual muchas veces se realizan aseveraciones con débil respaldo empírico.

¿Qué posición social ocupan los cónyuges de estas mujeres docentes, es decir, los jefes de los hogares donde habitan? ¿Se trata mayoritariamente de posiciones 
correspondientes a las capas acomodadas de la burguesía? Para aproximarnos al reclutamiento, utilizamos como referencia empírica la ocupación de estos jefes de hogar.

\section{Cuadro 2}

Jefes de hogar según composición social: Argentina (2001)

\begin{tabular}{|c|c|c|c|}
\hline \multicolumn{2}{|r|}{ Composición social } & $\mathrm{N}$ & $\%$ \\
\hline \multirow{4}{*}{ No asalariados } & Patrones de grandes empresas & 887 & 0,3 \\
\hline & Patrones de medianas y pequeñas empresas & 25.572 & 8,9 \\
\hline & Profesionales independientes y similares & 17.464 & 6,1 \\
\hline & Pequeños propietarios y trabajadores independientes & 43.519 & 15,1 \\
\hline \multirow{7}{*}{ Asalariados } & $\begin{array}{l}\text { Directivos de grandes empresas privadas y altos } \\
\text { funcionarios públicos }\end{array}$ & 3.136 & 1,1 \\
\hline & $\begin{array}{l}\text { Directivos de medianas y pequeñas empresas privadas } \\
\text { y de establecimientos públicos }\end{array}$ & 4.454 & 1,5 \\
\hline & Profesionales & 15.784 & 5,5 \\
\hline & Docentes & 23.529 & 8,2 \\
\hline & Técnicos de gestión administrativo contable y similares & 17.178 & 6,0 \\
\hline & Técnicos de la producción industrial y otros técnicos & 9.061 & 3,1 \\
\hline & Trabajadores de calificación operativa o sin calificación & 85.834 & 29,8 \\
\hline \multicolumn{2}{|l|}{ Desocupados } & 24.168 & 8,4 \\
\hline \multicolumn{2}{|c|}{ Jubilados y otros inactivos } & 17.629 & 6,1 \\
\hline & Total & 288.215 & 100,0 \\
\hline
\end{tabular}

Fuente: elaboración propia en base a Censo Nacional de Población, Hogares y Vivienda (2001).

El peso del elemento característico de las capas superiores de la pequeña burguesía, los patrones, es menor a una décima parte. Estas capas sociales están más bien representadas por la presencia de quienes ejercen funciones intelectuales: principalmente docentes ${ }^{6}$ y técnicos de gestión administrativo-contable, pero especialmente profesionales tanto independientes como asalariados. Estos grupos 
representan casi una cuarta parte del total. En el caso de los profesionales, más de la mitad corresponden a dos grandes grupos: por una parte, el constituido por abogados, contadores, administradores de empresas y otros profesionales relacionados con la gestión administrativa, jurídica, contable y financiera, y por otro, el conformado por médicos, farmacéuticos, veterinarios y otros profesionales de la salud y la sanidad.

\section{Cuadro 3}

Composición de los jefes de hogar profesionales asalariados e independientes: Argentina (2001)

\begin{tabular}{|l|r|r|}
\hline \multicolumn{1}{|c|}{ Composición } & $\mathrm{N}$ & \multicolumn{1}{c|}{$\%$} \\
\hline $\begin{array}{l}\text { Abogados, contadores, administradores de empresas y otros de la gestión } \\
\text { administrativa, jurídica, contable y financiera }\end{array}$ & 8.437 & 30,5 \\
\hline Médicos, farmacéuticos, veterinarios y otros de la salud y sanidad & 7.112 & 25,7 \\
\hline Arquitectos, ingenieros civiles y otros de la construcción e infraestructura & 2.694 & 9,7 \\
\hline Otros & 9.441 & 34,1 \\
\hline Total & 27.684 & 100,0 \\
\hline
\end{tabular}

Fuente: elaboración propia en base a Censo Nacional de Población, Hogares y Vivienda (2001).

Las capas inferiores de la pequeña burguesía están representadas principalmente por pequeños propietarios y trabajadores independientes que no contratan asalariados. Constituyen el 15\% de los jefes de hogar y su composición es heterogénea, destacándose una quinta parte de pequeños comerciantes.

\section{Cuadro 4}

Composición de los jefes de hogar pequeños propietarios: Argentina (2001)

\begin{tabular}{|c|c|c|}
\hline Composición & $\mathrm{N}$ & $\%$ \\
\hline Pequeños comerciantes & 11.481 & 21,8 \\
\hline Pequeños propietarios agropecuarios & 5.583 & 10,6 \\
\hline Pequeños propietarios de transporte & 6.215 & 11,8 \\
\hline Trabajadores independientes de la construcción & 5.640 & 10,7 \\
\hline $\begin{array}{l}\text { Trabajadores independientes de la producción industrial y artesanal } \\
\text { y de la reparación de bienes de consumo }\end{array}$ & 8.904 & 16,9 \\
\hline Otros pequeños propietarios y trabajadores independientes & 5.696 & 10,8 \\
\hline Total & 43.519 & 100,0 \\
\hline
\end{tabular}

Fuente: elaboración propia en base a Censo Nacional de Población, Hogares y Vivienda (2001). 
Por otra parte, parece existir un elemento proletario importante: casi un 30\% de trabajadores asalariados de calificación operativa o sin calificación. ${ }^{7}$ Este grupo está principalmente compuesto por oficinistas y empleados de comercio (cuatro de cada diez casos).

\section{Cuadro 5}

Composición de los jefes de hogar asalariados de calificación operativa o sin calificación: Argentina (2001)

\begin{tabular}{|l|r|r|}
\hline \multicolumn{1}{|c|}{ Composición } & N & \multicolumn{1}{c|}{$\%$} \\
\hline Personal auxiliar de tareas generales de oficina & 23.227 & 27,1 \\
\hline Empleados de comercio & 13.258 & 15,4 \\
\hline Choferes, conductores y otros empleados de transporte y almacenaje & 10.669 & 12,4 \\
\hline Obreros de la producción industrial y artesanal & 8.795 & 10,2 \\
\hline Personal de seguridad y suboficiales de fuerzas policiales y armadas & 6.616 & 7,7 \\
\hline Obreros de la construcción & 4.387 & 5,1 \\
\hline Resto & 18.882 & 22,0 \\
\hline Total & 85.834 & 100,0 \\
\hline
\end{tabular}

Fuente: elaboración propia en base a Censo Nacional de Población, Hogares y Vivienda (2001).

La mayoría son trabajadores de calificación operativa (78,5\%), sólo una minoría son no calificados. A su vez, en la mayor parte de los casos $(85,7 \%)$ se les realizan descuentos jubilatorios, por lo que se trata de asalariados registrados. Considerando esta situación como indicador de las condiciones en que logra vender su fuerza de trabajo, este grupo parece corresponder a las capas acomodadas del proletariado y no a las más pobres. Por su parte, una porción de dichas capas pobres puede estar presente entre el $8,4 \%$ de jefes de hogar que se encuentran desocupados. ${ }^{8}$

\section{Los jefes de hogar según grupo social}

A partir de la información presentada sobre la ocupación de estos jefes de hogares nos aproximamos al reclutamiento de las docentes mujeres cónyuges. Para esto, discriminamos la información presentada según "grupos sociales fundamentales", a partir de: la posición respecto de la propiedad o no propiedad de las condiciones materiales de existencia, y la función que representan en la producción y reproducción social, distinguiendo entre quienes cumplen o no funciones 
intelectuales de mando o auxiliares del capital en la estructura social. ${ }^{9}$ Estos grupos son los siguientes:

1) La gran burguesía y altos funcionarios constituyen la cúpula de la burguesía; los terratenientes, los magnates financieros, los grandes industriales, los rentistas, etc., es decir, la personificación del gran capital monopólico, ya sea porque por su posición son propietarios del gran capital o por su función constituyen el estado mayor que representa dichos intereses (por caso, altos directivos y gerentes).

2) La pequeña burguesía está constituida por propietarios de sus condiciones materiales de existencia, que no venden su fuerza de trabajo. Este grupo se encuentra en una situación de permanente diferenciación en dos grupos:

a) La pequeña burguesía acomodada está conformada por quienes, además de ser propietarios de sus propias condiciones materiales de existencia, son a su vez propietarios de los medios de vida y de trabajo de otros (pequeños y medianos patrones), pero también por quienes cumplen funciones de mando propias del capital aún bajo la forma jurídica del salario, ya sea que se encuentren insertos en la actividad económica o en el aparato administrativo estatal. Se trata de los "oficiales del ejército de la producción" (personal jerárquico y de jefatura media). Asimismo, tradicionalmente se han encontrado en este grupo quienes cumplen funciones auxiliares como intelectuales de la burguesía, aunque una parte de ellos puede estar inmersos en procesos de proletarización y/o pauperización; se incluyen aquí principalmente las siguientes categorías: profesionales independientes y asalariados (y por extensión quienes desempeñan funciones de asistencia técnico-profesional), quienes se desempeñan en funciones intelectuales auxiliares en el campo de la educación y la cultura (docentes, artistas, deportistas, periodistas, etc.) y quienes ejercen funciones superiores de apoyo administrativo, contable, jurídico y financiero (peritos, inspectores, técnicos contables, etc.).

b) La pequeña burguesía pobre se encuentra constituida por quienes son sólo propietarios de sus propios medios de vida y trabajo: pequeños comerciantes, trabajadores independientes de oficio y similares, etc. Atendiendo a su reclutamiento, una parte de quienes desempeñan funciones auxiliares de la burguesía ha sido asimilada a este grupo de pequeños propietarios pobres (técnicos industriales, personal paramédico), en tanto que, en parte se encuentran también inmersos en procesos de proletarización y/o pauperización. 
3) El proletariado y semiproletariado, constituido por quienes se encuentran expropiados total o parcialmente de sus condiciones de vida y de trabajo y que, en consecuencia, se ven obligados a vivir principal o parcialmente de la venta de su fuerza de trabajo, ya sea que logren venderla o no. Según esta conceptualización, el carácter proletario no depende de la actividad concreta realizada, sino de las relaciones sociales en que dicha actividad se encuentra inserta. Por esta razón, grupos tales como el personal auxiliar de oficina y los empleados de comercio son considerados como parte del proletariado. Aunque ya existen elementos teóricos respecto de rasgos proletarios de este tipo de ocupaciones en el siglo XIX (MARX, 1987, p. 293 y 371), serán las transformaciones producidas durante el siglo XX las que muestren cómo lo que a principios de ese siglo era percibido como un aumento de una creciente "clase media" se fue resolviendo en la formación de una nueva porción del proletariado a través de la polarización del trabajo de oficina, y cómo las ocupaciones ligadas al comercio minorista (y las de otros servicios) se extendieron bajo una forma capitalista, a la par que la población ocupada en ellas fue siendo reclutada del ejército de reserva producido por el estancamiento del empleo en otras ramas y caracterizada en gran parte por salarios bajísimos y por la escasa calificación, conocimiento y autoridad sobre los procesos de trabajo (BRAVERMAN, 1987). ${ }^{10}$

\section{Cuadro 6}

Docentes asalariadas mujeres cónyuges según grupo social del jefe de hogar: Argentina (2001)

\begin{tabular}{|c|c|c|}
\hline Grupo social fundamental del jefe de hogar & $\mathrm{N}$ & $\%$ \\
\hline Gran burguesía & 4.023 & 1,4 \\
\hline Pequeña burguesía acomodada & 103.981 & 36,1 \\
\hline Pequeña burguesía pobre & 52.580 & 18,2 \\
\hline Proletariado y semiproletariado & 110.002 & 38,2 \\
\hline No clasificable & 17.629 & 6,1 \\
\hline Total & 288.215 & 100,0 \\
\hline
\end{tabular}

Fuente: elaboración propia en base a Censo Nacional de Población, Hogares y Vivienda (2001).

En principio es posible observar efectivamente la fuerte presencia de docentes mujeres cónyuges cuyo reclutamiento corresponde a las capas superiores de la burguesía. Aquellas correspondientes a la gran burguesía o la pequeña burguesía 
acomodada constituyen casi un $40 \%$. Sin embargo, la presencia de docentes de extracción social proletaria y semiproletaria no puede ser subestimada, representan una proporción similar.

Sumadas aquellas docentes mujeres cónyuges enlazadas con porciones del proletariado y semiproletariado y la pequeña burguesía pobre, es decir, aquellas a quienes no se puede adjudicar su reclutamiento desde las capas acomodadas de la burguesía, superan la mitad de los casos.

\section{Resultados}

Los resultados parecen confirmar entonces el peso de la pequeña burguesía acomodada en el reclutamiento de las docentes mujeres cónyuges, pero también la existencia de elementos de un posible cambio en su extracción social, principalmente a través de la presencia de capas pobres de la pequeña burguesía y de elementos procedentes de las capas acomodadas del proletariado.

¿Qué expresan estos resultados? ¿Cómo pueden ser interpretados respecto de la pregunta relativa a las posibles transformaciones en la posición social de los docentes?

Uno de los procesos a los que se ha hecho clásicamente referencia en relación a la transformación de la posición social de quienes ejercen funciones y actividades profesionales o intelectuales, es aquel que remite a la erosión de la educación como privilegio de clase. Esta erosión es resultado de la extensión de la educación masiva y el consecuente y progresivo acceso a la educación elemental, pero también a la educación superior y a la categoría de intelectual, de capas de la masa del pueblo antes excluidas y habituadas a modos peores de vida. ${ }^{11}$ Sin embargo, este proceso parece referir a la tendencia a la pauperización de estos grupos, en tanto categorías sociales cuyas condiciones de vida las asimilaban a las capas acomodadas de la pequeña burguesía, pasarían tendencialmente a compartir condiciones de vida relativamente similares a las de las capas y fracciones que constituyen la masa del pueblo (principalmente, la pequeña burguesía pobre y las capas más acomodadas del proletariado). ${ }^{12}$

En todo caso, de confirmarse este proceso histórico, podrá afirmarse que existe una "proletarización" en su reclutamiento (en el sentido de que existe una mayor proporción de capas procedentes del proletariado entre aquellos que acceden a estas ocupaciones), pero esto no nos habla necesariamente de una proletarización de los docentes mismos en cuanto tales, en el sentido de que el hecho de que sus cónyuges sean proletarios no hace que ellos también lo sean necesariamente. En este sentido, entendemos que el acceso a la educación de determinadas capas y 
clases sociales anteriormente excluidas constituye un indicador de pauperización más que de proletarización, en tanto que remite específicamente a la esfera de las condiciones de vida de quienes acceden a la docencia, y en este sentido, nos indica hasta qué punto se ha popularizado la posibilidad de acceso a determinadas ocupaciones intelectuales, especialmente en un contexto de masificación del acceso al sistema educativo. ${ }^{13}$ Lo cual, nada nos dice acerca de que a la par se esté desarrollando efectivamente un proceso de proletarización de este grupo. En todo caso, los observables de dicho proceso deberán construirse a partir de otros indicadores.

Desafortunadamente, no contamos con la posibilidad de replicar el ejercicio aquí expuesto a partir de información de censos anteriores con el objetivo de construir una serie histórica. Sólo en el caso del Censo Nacional de Población, Hogares y Vivienda 2001 el Instituto Nacional de Estadística y Censos puso a disposición pública una base de datos que posibilitó el procesamiento de la información con la que aquí trabajamos. Para los censos anteriores sólo contamos con la información impresa, cuya forma de publicación no permite construir los datos para replicar la medición sobre la proporción de docentes mujeres cónyuges. Y, como señalamos, datos similares correspondientes al último censo de población realizado en el año 2010 aún no fueron publicados. ${ }^{14}$

De todas formas, sí es posible afirmar que resulta en principio incorrecta la imagen que asimila mecánicamente a las mujeres docentes cónyuges como enlazadas con aquella porción de la población que ocupa "posiciones relativamente importantes en la estructura social". A pesar de que la presencia de estas capas es innegable, esta representación puede corresponder, y hasta cierto punto, con la situación de las docentes en la Ciudad de Buenos Aires. Esto no obsta que en otros grandes centros urbanos pueda existir una composición similar, y en todo caso, habrá que profundizar el análisis en ese sentido. ${ }^{15}$ Sin embargo, en términos generales en el aspecto aquí analizado, las docentes mujeres cónyuges de esta Ciudad difieren claramente de las del conjunto del país, donde la situación se presenta mucho más heterogénea: la importante presencia de docentes mujeres cónyuges con extracción social desde el proletariado y la pequeña burguesía pobre parecería dar cuenta de que, en el sentido aquí expuesto, una porción importante de los docentes se encuentra en efecto relativamente pauperizados.

\section{Notas}

1. Los referentes más importantes de este debate han sido Braverman (1987) y Derber (1982). El primero sostiene la tesis de la existencia de un proceso de proletarización en tanto "descalificación" del trabajo, mientras que el segundo cuestiona dicha conceptualización y caracteriza la proletarización de los trabajadores intelectuales como un proceso "ideológico". Distintos autores han aplicado conceptos provenientes de una u otra teoría al caso específico de los docentes. Entre los partidarios 
de la hipótesis de la "descalificación” podemos citar a Apple (1994), Lawn y Ozga (1988) y Martínez Bonafé (1998), entre otros. En cambio, el concepto de la "proletarización ideológica" aplicado a los docentes, puede encontrarse en Contreras Domingo (1997) y Jiménez Jaén (1988). Para una descripción de estas posturas ver Donaire (2010a).

2. Entre dichos estudios podemos citar Ezpeleta (1991) y Martínez, Valles y Kohen (1997). También los estudios de Davini y Alliaud (1995) y Pineau et al. (2003). Estos últimos, a pesar de basarse en muestras representativas, cuentan con la limitación de que refieren más bien a los padres de los estudiantes que se forman para ser docentes, una buena parte de los cuales puede no llegar a terminar la carrera y por ende, no acceder al ejercicio de la docencia.

3. Estos resultados surgen de una investigación propia realizada mediante una encuesta aplicada en el año 2007 a una muestra de docentes de los niveles primario y secundario con cargos frente a alumnos en establecimientos de gestión pública y privada de educación común de la Ciudad de Buenos Aires (DONAIRE, 2012).

4. El único indicio existente que pudiera estar indicando un probable recambio generacional se relaciona con el restablecimiento a partir del año 2005 del régimen jubilatorio especial para docentes, el cual había sido eliminado en 1995. Este cambio normativo puede haber alentado un proceso masivo de jubilaciones y el reemplazo de los puestos que quedaron vacantes por otros docentes. De todas formas, no existe información respecto de qué grado ha alcanzado este proceso de renovación. Tampoco se conoce en qué proporción los puestos vacantes han sido ocupados por nuevos docentes o por docentes que ya se encontraban en ejercicio en otros puestos. Existen elementos para suponer cierta importancia de esta última posibilidad, en tanto el proceso de recambio se ha dado, al menos en la Ciudad de Buenos Aires, en el marco de una fuerte caída en el número de inscriptos para la carrera docente entre 2002 y 2007, especialmente en los profesorados de nivel inicial y primario (CASANOVAS, 7 de enero de 2007).

5. Existe una única fuente alternativa, el Censo Nacional de Docentes realizado por el Ministerio de Educación en 2004. Esta fuente cuenta con la ventaja de ser un poco más cercana en el tiempo y de intentar abarcar a todos aquellos que ejercen la docencia en forma asalariada, a diferencia del censo de población, que sólo considera la ocupación principal y, por ende, no permite abarcar a aquel conjunto de población que ejerce la docencia como ocupación secundaria. Sin embargo, a pesar de estas ventajas, el censo de docentes cuenta con información mucho más acotada sobre el hogar de los docentes. Por caso, respecto del cónyuge del docente, solo permite identificar su nivel educativo.

6. Puesto que lo que estamos analizando es precisamente hasta qué punto la extracción social de los docentes corresponde a la pequeña burguesía acomodada, en función de no forzar la hipótesis respecto de un posible cambio en dicha extracción, asumimos que los jefes de hogar que son ellos mismos también docentes constituyen parte de esa capa social.

7. Según la clasificación censal, se consideran ocupaciones de calificación operativa a aquellas que no requieren conocimientos teóricos para su ejercicio, pero sí de habilidades manuales o conocimientos específicos previos, mientras que se considera como no calificadas a aquellas que no requieren de ninguno de dichos elementos o solamente los provistos por una breve instrucción.

8. Aunque debe recordarse que el dato fue recolectado en un momento de alta desocupación abierta en Argentina: un 18,4\% de la población de los principales aglomerados urbanos a octubre de 2001 según la Encuesta Permanente de Hogares. De todas formas, si la disminución de la tasa de desocupación y, en menor medida, de la proporción de trabajo no registrado entre los asalariados, ocurridas con posterioridad a la crisis del 2001/02, han incidido de alguna manera en los rasgos de las ocupaciones de los jefes de hogar, esto probablemente acentuaría la extracción desde las capas proletarias acomodadas (en contraposición a las pobres) y reforzaría la hipótesis de que no ha habido cambios desde entonces, al menos a grandes rasgos, en la composición de estos jefes de hogar, y por ende, en la extracción de las mujeres docentes cónyuges. Como señalamos anteriormente, estos resultados deberán contrastarse a futuro con los resultados del censo de población del año 2010.

9. Para aproximarnos al análisis de los grupos sociales, tomamos como referencia el instrumento teórico-metodológico desarrollado por Iñigo Carrera y Podestá (1989), posteriormente revisado y 
actualizado en Donaire y Rosati (2010). La noción de "grupos sociales fundamentales" (GRAMSCI, 1997) utilizada aquí remite a las relaciones sociales objetivas en que determinadas porciones de población reproducen su existencia, y por ende, al análisis de la estructura social. Se diferencia así respecto del concepto de "clases sociales", las cuales, en sentido estricto, se constituyen en los enfrentamientos sociales (ver MARX; ENGELS, 1982).

10. En el caso argentino, este carácter proletario aparece tempranamente expresándose en el uso de la huelga como instrumento de lucha, la conformación de sindicatos propios y la adhesión de estas organizaciones a las organizaciones nacionales del conjunto del movimiento obrero. Una reseña histórica sobre los casos de los empleados de comercio y los empleados bancarios, puede encontrarse en Adamovsky (2009).

11. “[...] el mayor obstáculo que separa a los intelectuales del proletariado es que los primeros forman una clase privilegiada: su privilegio es la educación. Sin duda tiene mucho interés en que la cultura de la masa del pueblo sea suficiente para que se penetre de la importancia de la ciencia y se incline ante ella y ante sus representantes; pero su interés les recomienda también que se opongan a todos los esfuerzos que tiendan a aumentar el número de los que disfrutan de una buena educación profesional. Sin duda la forma de producción capitalista necesita un gran número de intelectuales. Las instituciones escolares del Estado feudal no los producen en número suficiente. El régimen burgués se ve, pues, obligado a mejorar y extender no tan sólo la enseñanza elemental, sino también la enseñanza superior. Con esto se creía que además de favorecer el desarrollo de la producción, se atenuaban más todavía los antagonismos de clase, porque si una mayor cultura elevaba a una situación burguesa, parecía natural que la vulgarización de la instrucción elevase al proletariado a las condiciones de la vida burguesa. Pero el 'standard of life' burgués no es sino la consecuencia necesaria de una alta cultura allí donde ésta es un privilegio. Donde en general no eleva a los proletarios al rango de burgueses, lo que hace es que rebaja a los trabajadores intelectuales al nivel de los proletarios. He aquí una nueva faz del 'crecimiento de la miseria' de la masa del pueblo" (KAUTSKY, 1966, p. 170).

12. Utilizamos aquí la expresión "masa del pueblo" en el sentido de lo que clásicamente se ha denominado como "masa trabajadora y explotada", conjunto constituido por quienes, sean o no propietarios de sus condiciones de existencia, es decir sean proletarios o pequeños propietarios, reproducen su vida por su propio trabajo y son explotados o expoliados por diversos mecanismos.

13. Considérese que, mientras que en 1960 sólo el 5,7\% de la población mayor de 14 años en Argentina había alcanzado el nivel secundario completo (es decir, el destinado en el sistema educativo a los adolescentes entre los 13 y 18 años de edad) y sólo el 1,4\% había completado el nivel superior, en 2001 ambas proporciones se elevan al 24,5\% y 8,7\% respectivamente (IÑIGO, 2004).

14. Una descripción de las variaciones en el reclutamiento de los docentes en el largo plazo sólo puede ser reconstruida - y de manera muy fragmentaria - a partir de diversas fuentes. Un intento de realizar esa reconstrucción histórica puede encontrarse en Donaire (2009).

15. Un primer ejercicio ha sido la comparación entre la Ciudad de Buenos Aires y los Partidos del Conurbano Bonaerense. Los resultados del mismo permiten formular la hipótesis de que el elemento de extracción pequeñoburguesa acomodada entre las mujeres docentes cónyuges tiende a ser mayor entre los distritos donde esta capa social alcanza mayor peso relativo en el conjunto de la población (DONAIRE, 2010c).

\section{Referencias}

ADAMOVSKY, E. Historia de la clase media argentina: apogeo y decadencia de una ilusión, 1919-2003. Buenos Aires: Planeta, 2009.

APPLE, M. Educación y poder. Barcelona: Paidos; MEC, 1994. 
BRASLAVSKY, C.; BIRGIN, A. ¿Quiénes enseñan hoy en la Argentina? In: TIRAMONTI, G.; BRASLAVSKY, C.; FILMUS, D. (Comp.). Las transformaciones de la educación en 10 años de democracia. Buenos Aires: Flacso Educación; Tesis, 1995. p. 65-106.

BRAVERMAN, H. Trabajo y capital monopolista. México, DF: Nuestro Tiempo, 1987.

CASANOVAS, L. Decae el interés por ser docente. La Nación, Buenos Aires, 7 de enero de 2007. Disponível em: <http://www.lanacion.com.ar/873339-decae-el-interespor-ser-docente>.

CONTRERAS DOMINGO, J. La autonomía del profesorado. Madrid: Morata, 1997.

DAVINI, M.C.; ALLIAUD, A. Los maestros del siglo XXI: un estudio sobre el perfil de los estudiantes de magisterio. Buenos Aires: Miño y Dávila, 1995.

DERBER, C. Professionals as workers: mental labor in advanced capitalism. Boston: G.K. Hall, 1982.

DONAIRE, R. La clase social de los docentes: condiciones de vida y de trabajo en Argentina desde la colonia hasta nuestros días. Buenos Aires: Ctera, 2009.

DONAIRE, R. La posición social de los docentes: una aproximación a partir del estudio de los docentes de la ciudad de Buenos Aires. Revista de Educação, Campinas, n. 28, p. 113-129, jan./jun. 2010a.

DONAIRE, R. La extracción social de los docentes: una comparación según provincias. Trabalho apresentado na 6. Jornadas de Sociología, Universidad Nacional de La Plata, La Plata, 9 y 10 de diciembre de 2010b.

DONAIRE, R. La extracción social de los docentes: una comparación entre la ciudad de Buenos Aires y los Partidos del Conurbano Bonaerense. Trabalho apresentado nas Segundas Jornadas Nacionales de Investigadores en Formación en Educación, Instituto de Investigaciones en Ciencias de la Educación (IICE) de la Facultad de Filosofía y Letras de la Universidad de Buenos Aires, Buenos Aires, 29 y 30 de noviembre de 2010c.

DONAIRE, R. Los docentes en el siglo XXI: ¿Empobrecidos o proletarizados? Buenos Aires: Siglo XXI, 2012.

DONAIRE, R.; ROSATI, G. Evolución de la distribución de la población según grupos sociales fundamentales, Argentina (1960-2001). Pimsa Documentos y Comunicaciones 2008/9, Buenos Aires, n. 12, p. 8-22, 2010

DONAIRE, R.; ROSATI, G. Estructuras económico sociales concretas que constituyen la formación económica de la Argentina (1980-2001). Pimsa Documentos y Comunicaciones 2010, Buenos Aires, n. 13, p. 50-103, 2012. 
EZPELETA, J. Escuelas y maestros. Condiciones de trabajo docente en Argentina. Santiago de Chile: Unesco/Orealc, 1991.

GRAMSCI, A. Notas sobre Maquiavelo, sobre la política y sobre el Estado moderno. Buenos Aires: Nueva Visión, 1997.

IÑIGO, L. Extensión de la escolaridad promedio en la Argentina: ¿producción de atributos productivos de la fuerza de trabajo? Trabalho apresentado no Congreso Internacional de Sociología de la Educación, Facultad de Filosofía y Letras, Universidad de Buenos Aires, 25 al 28 de agosto de 2004.

IÑIGO CARRERA, N.; PODESTÁ, J. Análisis de una relación de fuerzas sociales objetiva: caracterización de los grupos sociales fundamentales en la Argentina actual. Cuadernos de Cicso, Buenos Aires, 1989. (Estudios n. 46).

JIMÉNEZ JAÉN, M. Los enseñantes y la racionalización del trabajo en educación: elementos para una crítica de la teoría de la proletarización. Revista de Educación, Madrid, n. 285, p. 231-245, ene./abr. 1988.

KAUTSKY, C. La doctrina socialista. Buenos Aires: Claridad, 1966.

LAWN, M.; OZGA, J. ¿Trabajador de la enseñanza?: nueva valoración de los profesores. Revista de Educación, Madrid, n. 285, p. 191-215, ene./abr. 1988.

LLOMOVATE, S. Estado del arte sobre condiciones laborales docentes en Argentina. In: FRIGERIO, G. et al. El sistema educativo como ámbito laboral. Buenos Aires: Universidad de Buenos Aires, 1995. p. 149-168.

MARSHALL, A. El empleo en el sector educativo. Buenos Aires: Dirección Red Federal de Información Educativa, Ministerio de Cultura y Educación de la Nación, 1999. (Serie Estudios Especiales, Documento n. 1).

MARTÍNEZ, D.; VALLES, I.; KOHEN, J. Salud y trabajo docente: tramas del malestar en la escuela. Buenos Aires: Kapelusz, 1997.

MARTÍNEZ BONAFÉ, J. Trabajar en la escuela: profesorado y reformas en el umbral del siglo XXI. Madrid: Miño y Dávila; Instituto de Investigaciones en Ciencias de la Educación (UBA), 1998.

MARX, K. El capital: crítica de la economía política. México, DF: Fondo de Cultura Económica, 1987. v. 3.

MARX, K.; ENGELS, F. La ideología alemana. La Habana: Pueblo y Educación, 1982.

NARODOWSKI, M. Ser maestro en la Argentina. Buenos Aires: Suteba, 1990.

PINEAU, P. et al. Docentes con raros peinados nuevos: el perfil de los estudiantes de 
primer año de las carreras de formación docente de la Ciudad de Buenos Aires. Trabalho apresentado no Encuentro de Formadores-as de Docentes de la Ciudad de Buenos Aires: experiencias y perspectivas, Buenos Aires, 30 de octubre al $1^{\circ}$ de noviembre de 2003.

TENTI FANFANI, E. La condición docente: análisis comparado de la Argentina, Brasil, Perú y Uruguay. Buenos Aires: Siglo XXI, 2005.

Recebido em 10 de junho de 2011.

Aprovado em 22 de junho de 2012. 